\title{
ESTIMASI PERHITUNGAN BANDWIDTH UNTUK AKSESIBILITAS APLIKASI BERBASIS WEB
}

\author{
Ariyanto Umar ${ }^{1)}$, Roys Pakaya ${ }^{2)}$, Irwan Karim ${ }^{3)}$ \\ Program Studi Teknik Informatika, \\ Politeknik Gorontal, 60111, \\ email :ariyantoumar.xo@gmail.com, royspakaya@poligon.ac.id, irwankarim@poligon.ac.id
}

\begin{abstract}
Abstrak-Perkembangan teknologi serta perangkat telekomunikasi pada saat ini berkembangdengan $p$ esat. Beragam inovasi media transmisi maupun perangkat telekomunikasi semakinkompleks dan beragam. Saat ini penyebaran jaringan internet telah mengalami perkembanganyang sangat signifikan. Internet telah menjadi media utama bagi masyarakat di zaman sekarang untuk memenuhi kebutuhan akan akses informasi bahkan hingga ke penggunaan aplikasi yang tidak lagi bersifat lokal, melainkan sudah bersifat daring. Dari sekian banyak penggunaan internet, banyak yang tidak peduli dengan seberapa besar konsumsi mereka selama beraktifitas. Konsumsi yang di maksud adalah konsumsi bandwidth yang merupakan faktor dominan dalam beraktifitas di dunia daring. Apalagi sampai memperhatikan berapa sebenarnya bandwidth yang di pergunakan untuk mengakses suatu aplikasi, entah itu yang berbasis web maupun yang berbasis mobile. Akibatnya timbul permasalahan baru, sering terjadi kongesti atau kejenuhan jaringan. Dan hasilnya, aktifitas jadi terhambat. . Untuk menemukan jalan keluar atau pun solusi dari suatu permasalahan tersebut. Penulis akan mencoba melakukan suatu penelitian yang bertujuan bagaimana cara agar kita dapat mengetahui berapa kebutuhan bandwidth yang akan di pakai untuk mengakses aplikasi berbasis web.

Kata Kunci : Estimasi Bandwidth, Aplikasi berbasis Web
\end{abstract}

\section{PENDAhuluan}

Teknologi Informasi saat ini bukan lagi merupakan hal yang asing. Segala aspekmulai dari pendidikan, kesehatan, publikasi, administrasi perkantoran, transaksijual beli, sampai dengan sosialisasi sehari-hari sudah di dukung oleh teknologiinformasi.Meningkatnya kebutuhan akan teknologi informasi ini bisa dilihat darijumlah user internet di Indonesia, dimana pada tahun 2010 telah mencapai angka45.000.000 jiwa dan diperkirakan akan mencapai angka 130.000.000 jiwa di tahun2014 (Setiawan, 2013).

Dari sekian banyak pengguna internet, tidak banyak yang peduli dengan seberapa besar konsumsi mereka selama beraktifitas. Konsumsi yang dimaksud adalah konsumsi bandwidthyang merupakan faktor dominan dalam beraktifitas di dunia daring. Apalagi sampai memperhatikan berapa sebenarnya bandwidth yang mereka pergunakan untuk mengakses suatu aplikasi, entah itu yang berbasis web maupun yang berbasis mobile. Akibatnya timbul permasalahan baru, sering terjadi kongesti atau kejenuhan jaringan. Dan hasilnya, aktivitas jadi terhambat.

Dalam penelitian ini nantinyaakan dilakukan penelitian yang dimana bertujuan untuk menghitung estimasi dari bandwidth saat melakukan aksesibilitas terhadap sebuah aplikasi berbasis web. Sehingga dari penelitian ini diharapkan akan diperoleh angka perkiraan rata-rata berapa sebenarnya bandwidth yang dibutuhkan untuk mengkases sebuah aplikasi berbasis web tersebut.

Dalam hal ini adalah aplikasi berbasis web yang dihosting di sebuah server. Berdasarkan pada uraian pada paragraf-paragraf sebelumnya maka yang menjadi usulan judul penelitian penulis yakni tentang "Estimasi Perhitungan Bandwidth Untuk Aksesibilitas Aplikasi Berbasis Web".

\section{METODE PENELITIAN}

Penelitian ini menggunakan metodologi eksperimen yang terdiri dari 7 (tujuh) tahapan, ditunjukkan pada gambar 1:

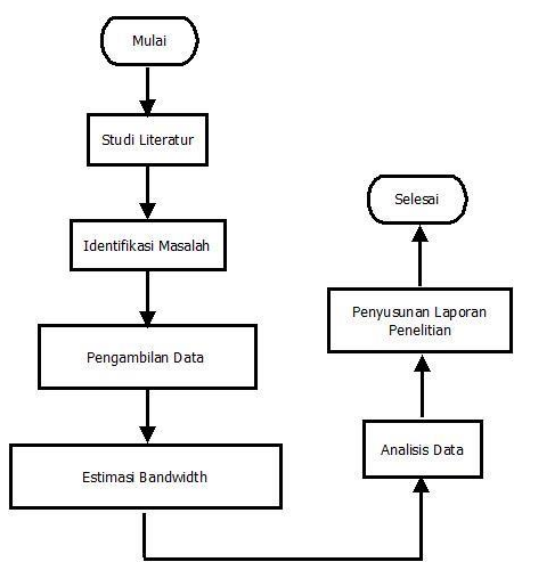

Gambar 1. Teknik pengumpulan data (Deni Kuswoyo, 2015)

Deskripsi dari Gambar 1 adalah sebagai berikut ini :

Tahap pertama Mempelajari studi dan analisa dari beberapa penelitian sebelumnya yang berkaitan dengan sistem aplikasi dan pengujian sistemnya. Selanjunya, 
mengidentifikasi masalah yang ada. kemudianpengambilan data dilakukan dengan cara melakukan observasi pada traffic penggunaan bandwidthyang ada pada server untuk mempelajari kriteria-kriteria yang dibutuhkan.

Perhitungan akan dilakukan menggunakan sistem aplikasi yang dipakai, dengan melihat trafik penggunaan bandwidth terhadap sebuah aplikasi web tersebut. Setelah itu menganalisis data yang telah didapatkan dan melakukan penyusunan laporan berdasarkan penelitian yang sudah dilakukan.

\section{A. Kualitas Layanan}

Sebuah aplikasi dapat beroperasi dengan baik apabila dapat dikontrol dari segi akses, pelayanan, dan performanya.

Menurut (Mohamad Ibrahim Ladan, 2011) Kualitas layanan pada layanan web terbagi dalam beberapa hal antara lain:

- Accessibility

Kemampuan layanan web dalam melayani permintaan klien

- Reliability

Kemampuan layanan web untuk melaksanakan fungsinya pada interval waktu tertentu

\section{- Performance}

(Menurut Kuyoro Shade, 2012) kemampuan kinerja layanan web direpresentasikan dengan kecepatan layanan dalam menyelesaikan permintaan klien.

Pengukuran kinerja layanan web dapat dilakukan berdasarkan:

a. response time yaitu lama waktu yang dibutuhkan untuk menyelesaikan permintaan

b. throughput yaitu jumlah permintaan yang dapat diselesaikan dalam periode tertentu

c. latency yang merupakan lama waktu yang diperlukan dari pengiriman permintaan oleh klien sampai menerima hasil permintaan tersebut dari server.

\section{B. Infrastruktur}

Berikut beberapa hardware komponen yang akan digunakan sebagai infrastruktur yaitu:

- Network

Jaringan Komputer adalah sebuah sistem yang terdiri atas komputer dan perangkat jaringan lainnya yang bekerja bersama-sama untuk mencapai suatu tujuan yang sama.

Tujuan dari jaringan komputer adalah ini adalah:

a. Membagi sumber daya : Pemakaian CPU, Printer, Harddisk, Memory

b. Komunikasi : email, instant messaging, chatting

c. Akses informasi : web browsing

d. CPU (Central Processing Unit

CPU adalah komponen pengolah data berdasarkan instruksi-instruksi yang diberikan kepadanya. Pada dasarnya fungsi CPU adalah menjalankan program-program yang disimpan dalam memori utama dengan cara mengambil instruksi-instruksi, menguji instruksi tersebut dan mengeksekusinya satu persatu sesuai alur perintah (Retno, 2012).

e. Memory

Memory berfungsi sebagai tempat penyimpanan data, memory dibagi menjadi dua yaitu bersifat sementara (RAM) dan permanen (Harddisk).

f. RAM (Random Access Memory)

RAM merupakan singkatan dari Random Access Memory yang berfungsi untuk menyimpan data atau instruksi sementara.

g. Hardisk

Hardisk adalah salah satu perangkat keras komputer yang digunakan untuk menyimpan data secara permananen.

Tabel Spesifikasi perangkat keras yang digunakan:

\begin{tabular}{|l|l|}
\hline $\begin{array}{l}\text { Perangkat } \\
\text { Keras }\end{array}$ & Server \\
\hline CPU & $\begin{array}{l}\text { AMD Dual-Core Processor E1-2500 } \\
\text { (1.4 Ghz) }\end{array}$ \\
\hline Memory & 2GB DDR3 L Memory \\
\hline Harddisk & 500 GB HDD \\
\hline
\end{tabular}

\section{Estimasi Bandwidth}

Perhitungan dapat diketahui dengan melihat bandwidthyang digunakan oleh client untuk mengakses sebuah aplikasi berbasis web yang dipantau langsung menggunakan goaccess. Pemakaian bandwidth tersebut ditampilkan dengan model grafik serta dengan nilai pemakaiannya. Goaccess digunakan agar dapat memantau segala jenis aktivitas client yang mengakses sebuah aplikasi berbasis web serta dapat menampilkannya per hostname sehingga dapat diketahui berapa sebenarnya bandwidth yang digunakan.

Berdasarkan penggunaan tersebut seorang administrator jaringan dapat menentukan besaran bandwidth yang diperlukan untuk mengakses sebuah aplikasi berbasis web.

\section{IMPLEMENTASI}

Setelah melakukan melakukan isntalasi goaccess sebagai media untuk melihat trafficpenggunnaan bandwidth terhadap sebuah aplikasi berbasis web:

Langkah-langkah yang digunakan pada goaccess terdiri dari access log apache, report web access, konfigurasi apache virtual host, run goaccess. 
aricubuntu:/usr/local/srç ls /var/www/goaccess/ index.html

Gambar 2. Report Web GoAcceess

Gambar 2. merupakan perintah report web dari goaccess atau pemanggilan web goaccess yang akan dijalankan menggunakan browser.

\section{ariCubuntu: "`S sudo nano /etc/apache2/sites-available/000-def ault.c}

Gambar 3. Konfigurasi Apache Virtual Host

Gambar 3 merupakan perintah untuk mengkonfigurasi Apache Virtual Host

goaccess -f /var/log/apache2/access.log

\section{Gambar 4. Run GoAccess Terminal}

Gambar 4 merupakan tampilan perintah untuk menjalankan goaccess secara real-time pada terminal

\section{Goaccess Terminal}

Pada tampilantersebut goaccess dijalankan menggunakan terminal untuk menampilkan pemakaian terhadap sebuah aplikasi berbasis web yang diuji dan menampilkannya secara real-time.

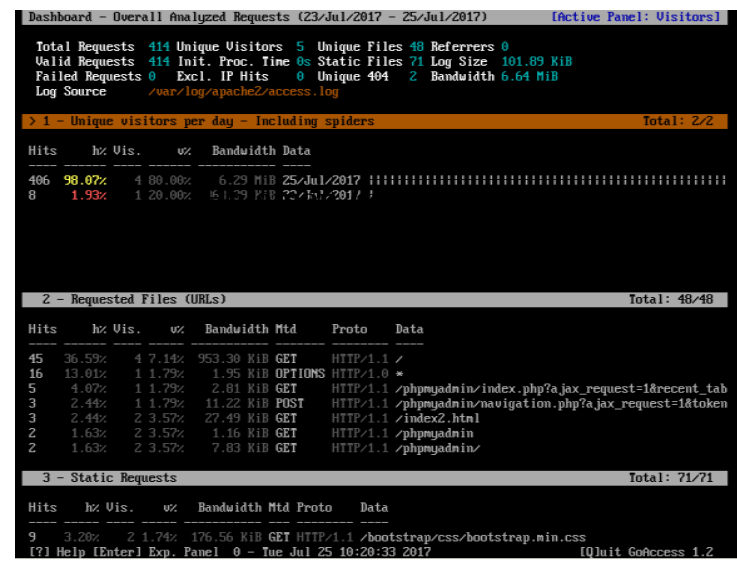

Gambar 5. Tampilan GoAccess pada Terminal

Gambar 5 merupakan tampilan pada saat goaccess dijalankan pada terminal secara real-time.

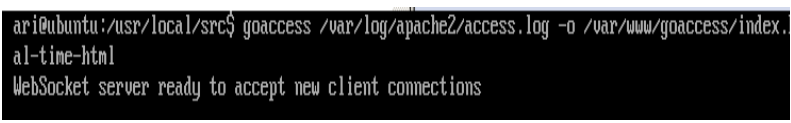

Gambar 6. GoAccess Real-Time

Gambar 6. merupakan tampilan perintah goaccess yang akan dibuat secara real-time pada tampilan server static goaccess yang dijalankan menggunakan browser.

\section{E. Dashboard}

Pada tampilan dashboard tersebut menampilkan pemakaian terhadap sebuah aplikasi web yang diuji secara real-time yang dijalankan menggunakan webbrowser.

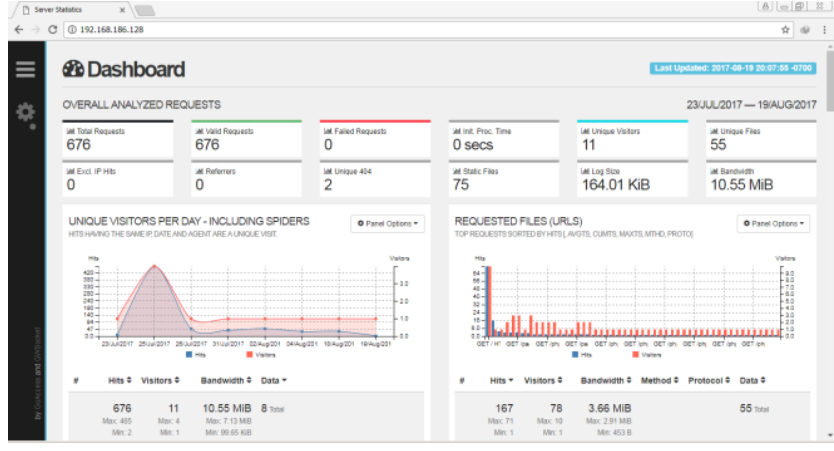

Gambar 7. Tampilan Server Static GoAccess RealTime

Gambar 7. merupakan tampilan server static goaccess yang dijalankan menggunakan browser secara real-time.

F. Unique Visitiors

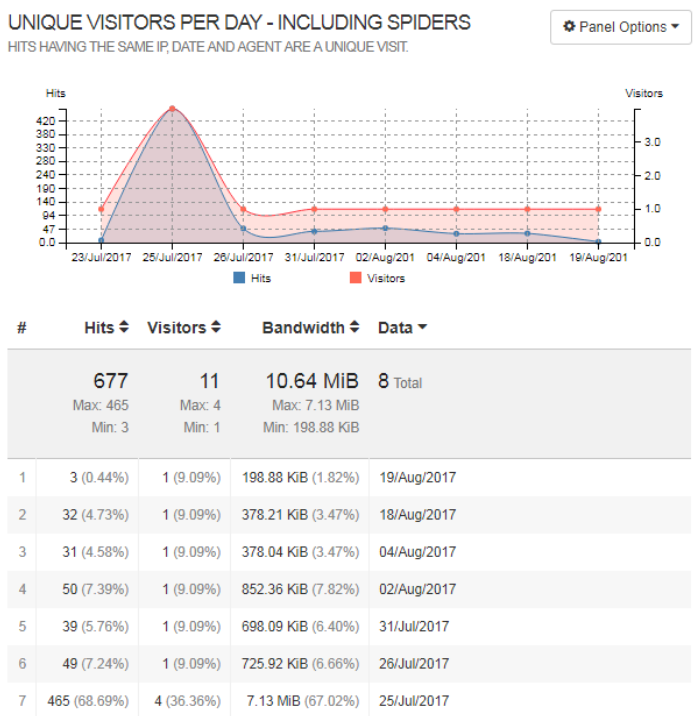

Gambar 8. Tampilan pengunjung per tanggal

Gambar 8. menunjukkan pengunjung dan bandwidth kumulatif yang ditampilkan per tanggal.

G. Requested Files

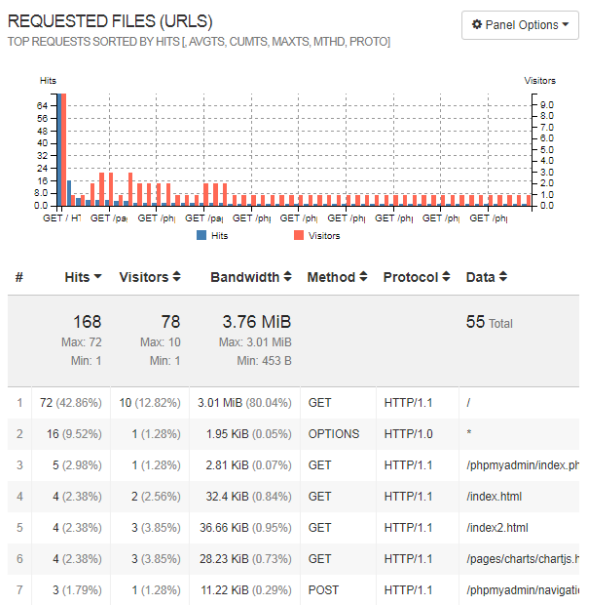


Gambar 9. Tampilan file yang banyak diakses

Gambar 9. menampilkan file yang paling banyak diminta di serverweb. Ini menunjukkan hits, pengunjung unik, dan persentase, bersamaan dengan bandwidth kumulatif, protokol, dan metode permintaan yang digunakan.

\section{H. Hostname}

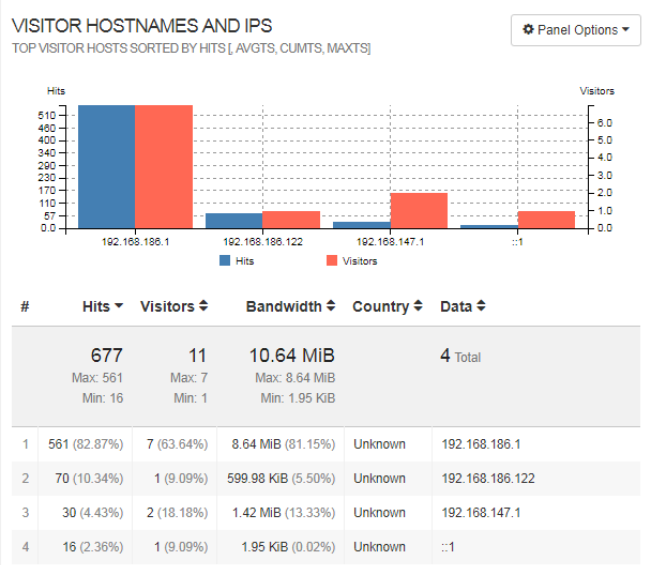

Gambar 10. Tampilan hostname

Gambar 10. menampilkan informasi secara rinci tentang host dan juga IP yang digunakan serta pemakaiannya.

\section{PENUTUP}

Setelah melakukan analisa pemakaian bandwidth terhadap setiap user/pengguna, penulis menyimpulkan dari hasil analisa dan pembahasan bahwa:

\section{Kesimpulan}

Penulis menyimpulkan dari hasil analisa dan pembahasan bahwa:

1. Jumlah pengguna yang mengakases berhasil diketahui sebanyak 3 hostname.

2. Traffic penggunaan bandwidth tertinggi berdasarkan total keseluruhan kunjungan sebesar 825.36 Kb dengan jumlah hits sebesar 50 .

3. Jumlah bandwidth yang digunakan berdasarkan per hostname dengan satu kali kunjungan yaitu sebesar $599.98 \mathrm{~Kb}$.

\section{Saran}

Adapun saran yang dapat diberikan sehubungan dengan pelaksanaan penelitian ini adalah:

1. Untuk estimasi bandwidth dapat dikembangkan lagi dengan mengestimasi beberapa aplikasi berbasis web tertentu yang banyak diakses oleh khalayak umum.

2. Dalam pengembangan penelitan selanjutnya dapat menghitung peak hour dan memperhitungkan latency maupun package loss yang terjadi.

\section{DAFTAR PUSTAKA}

Bayunadi, I., Rochim, A. F., \& Satoto, K. I. (n.d.). Network Monitoring Service Berbasis Simple Network Management Protocol Menggunakan Aplikasi Cacti.

Canonical Ltd. (2017). About Ubuntu.

Deni Kuswoyo, N. A. (2015). Model Perhitungan Kebutuhan Bandwidth Jaringan Komputer menggunakan Sistem Pakar Fuzzy dengan Metode Adaptive Neuro Fuzzy Inference System ( ANFIS ) :, 3(Teknik Informatika), 1-15.

Muhammed, D. (2010). Buku Pintar Internet Optimasi Akses Internet. Jakarta:

Faizal, H (2015). Teknik Dan Masalah Dalam Menentukkan Estimasi. Semarang:

Gerardo orellana. (2017). Description Goaccess, https://goaccess.io/man\#description (diakses pada tanggal 29 juli 2017)

Rouse, N.B., (2011), Pengertian Aplikasi Berbasis Web. Graha Ilmu. Yogyakarta

Santosa, B, 2004, Management BandwithInternet dan Intranet,

http://kambing.ui.ac.id/onnopurbo/library/libraryref-ind/ref-ind-2/network/bwmanagement.pdf (diakses pada tanggal 6 Februari 2017)

Setiawan, D. (2013). National Broadband Plan Case of Indonesia. KnowledgeSharing on Australia Broadband (hal. 2). Jakarta: Director General ofResources and Standard, Ministry of Communication and IT.

Mohamad Ibrahim Ladan,. Ph.D. 2011. Web Services Metrics A Survey and A Classification, International Conference on Network and Electronics Engineering IPCSIT vol.11 (2011) (C) (2011) IACSIT Press, Singapore

Kuyoro Shade O. 2012. Quality of Service (Qos) Issues in Web Services, IJCSNS International Journal of Computer Science and Network Security, VOL.12 No.1, January 2012

Retno. 2012. Struktur CPU Pada Komputer. Universitas Indraprasta PGRI Vol.2 